\section{Consumo de aditivos alimentares e efeitos à saúde: desafios para a saúde pública brasileira}

\author{
Food additive intake and health effects: \\ public health challenges in Brazil
}

\footnotetext{
1 Escola de Nutrição, Universidade Federal do Estado do Rio de Janeiro, Rio de Janeiro, Brasil. 2 Escola Nacional de Saúde Pública Sergio Arouca, Fundação Oswaldo Cruz, Rio de Janeiro, Brasil.

Correspondência M. L. T. Polônio Escola de Nutrição, Universidade Federal do Estado do Rio de Janeiro. Av. Pasteur 296, Rio de Janeiro, $R J$ 22290-180, Brasil. lpolonio@terra.com.br
}

\begin{abstract}
This study uses a systematic literature review to contextualize the risks associated with food additive intake. Studies comparing food additive intake and cancer showed that adverse health effects appeared when Acceptable Daily Intake (ADI) was exceeded. The review also detected a lack of studies on attention deficit-hyperactivity disorder. There were more studies on non-specific hypersensitivity, highlighting such clinical manifestations as rhinitis, urticaria, and angioedema, all associated with food additives, particularly artificial colorants. Children are a vulnerable group as potential consumers of food additives, particularly artificial colorants. Studies on food additive intake should provide the basis for effective food and nutritional surveillance strategies, aiming to promote healthy eating habits.
\end{abstract}

Food Additives; Nutritional Surveillance; Chronic Disease; Food Habits
Maria Lúcia Teixeira Polônio 1,2

Frederico Peres 2

\section{Introdução}

A mudança no hábito alimentar da população brasileira, ocorrida nas últimas décadas, tem atraído a atenção dos órgãos reguladores e da comunidade científica como um todo, pois a substituição de alimentos in natura por alimentos processados vem contribuindo de forma contundente para o empobrecimento da dieta. Conseqüentemente, tal fato contribui, também, para o aparecimento de doenças crônicas nãotransmissíveis, responsáveis, principalmente, pelas doenças do aparelho circulatório, diabetes e neoplasias, resultado das modificações no padrão de adoecimento global na segunda metade do século XX. As doenças crônicas não-transmissíveis apresentam etiologia multifatorial e estão associadas a fatores de riscos ambientais e comportamentais, como a alimentação inadequada, a obesidade, as dislipidemias, o tabagismo e a inatividade física 1 .

Além de a dieta ter sofrido modificações ao longo do tempo, a tecnologia aplicada pela indústria de alimentos com o intuito de aumentar o tempo de vida útil desses produtos tem gerado questionamentos quanto à segurança do emprego de aditivos alimentares, fundamentalmente quando se trata de corantes artificiais 2 .

A avaliação dos aditivos alimentares no âmbito mundial é baseada no controle das IDAs (Ingestão Diária Aceitável), desenvolvida pelo Comitê de Expertos em Aditivos Alimentares 
da Organização Mundial da Saúde (OMS)/Organização das Nações Unidas para Agricultura e Alimentação (FAO) [The Joint FAO/WHO Expert Committee on Food Additives - JECFA]. Esse comitê define aditivo alimentar como qualquer substância que enquanto tal não se consome normalmente como alimento, nem tampouco se utiliza como ingrediente básico em alimentos, tendo ou não valor nutritivo, e cuja adição intencional ao alimento com fins tecnológicos (incluindo os organolépticos) em suas fases de fabricação, elaboração, preparação, tratamento, envasamento, empacotamento, transporte ou armazenamento, resulte ou possa preservar razoavelmente por si, ou seus subprodutos, em um componente do alimento ou um elemento que afete suas características 3 .

Diversos estudos apontam reações adversas aos aditivos, quer seja aguda ou crônica, tais como reações tóxicas no metabolismo desencadeantes de alergias, de alterações no comportamento, em geral, e carcinogenicidade, esta última observada a longo prazo 4,5,6,7,8,9.

Nesses, destacamos aqueles relacionados à saúde infantil, preocupação que encontra respaldo no fato de ser esta categoria uma das mais, senão, a maior consumidora desses produtos. Nesse sentido, vale ressaltar que as crianças apresentam maior suscetibilidade às reações adversas provocadas pelos aditivos alimentares. Inegavelmente, o uso dessas substâncias e seus efeitos deletérios devem considerar também a freqüência com que os aditivos são consumidos, assim como sua quantidade por $\mathrm{kg} /$ peso.

Outro fator que merece destaque é o da imaturidade fisiológica, que prejudica o metabolismo e a excreção dessas substâncias. Além disso, a criança não tem capacidade cognitiva para controlar um consumo regular tal como deveria fazer um adulto.

Ainda considerando aspectos da saúde infantil, o JECFA 10 recomenda que não sejam utilizados aditivos intencionais em alimentos destinados a crianças menores de um ano, respeitando, assim, o Codex Alimentarius. Apesar dessa orientação, existem vários produtos no mercado, como iogurtes, gelatinas, refrigerantes, biscoitos, balas, dentre outros, que são consumidos tanto por crianças como por adultos, e que não estão sujeitos à referida normatização, o que torna a criança mais vulnerável.

Nesse sentido, este estudo visa a contextualizar, por meio de uma revisão sistemática da literatura, os riscos acarretados pelo consumo de aditivos alimentares como um dos grandes desafios da Saúde Pública, evidenciando possíveis indicativos de vulnerabilidade para grupos populacionais específicos, como as crianças.

\section{Metodologia}

O presente estudo compreende uma revisão sistemática da literatura sobre o tema "consumo de aditivos alimentares e saúde". Segundo Mulrow 11, a revisão sistemática é uma abordagem metodológica através da qual o conhecimento científico disponível é organizado e integrado, com o intuito de fornecer dados para o processo de tomada de decisões. Estabelece a consistência do conhecimento cientifico, apontando quando determinado fenômeno observado pode ser generalizado para um grupo ou população em geral.

De acordo com Mulrow 11, os pressupostos metodológicos que sustentam essa abordagem são:

1) Abundância de informação disponível leva à necessidade de se organizar e resumir os dados. Por meio de uma exploração crítica e sintética, é possível separar dados insignificantes e abrangentes demais do objeto do trabalho em questão;

2) No processo de tomada de decisão há a necessidade de se integrar uma série de dados, consolidando um foco no objeto do trabalho em questão. Assim, é possível identificar, justificar e refinar hipóteses, reconhecer os limites e barreiras dos trabalhos prévios, estimar o tamanho de amostras e reformular guias e legislação disponíveis;

3) A revisão sistemática é um método eficiente, freqüentemente mais rápido e menos custoso que um estudo empírico novo;

4) A revisão sistemática consegue identificar as generalizações dos dados e dos achados científicos, provendo um contexto interpretativo dos múltiplos estudos revisados, impossível de se obter com a análise de um único estudo ou estudos isolados; e

5) A revisão sistemática permite avaliar a consistência das relações. Consegue identificar consistência entre estudos realizados com a mesma ou diferentes intervenções. Por corolário, permite identificar inconsistências e conflitos entre os diferentes dados disponíveis.

Para a elaboração da referida revisão foram consultadas bases de dados MEDLINE, LILACS e SciELO, no período de 1988 a 2007. Ao todo foram identificados 224 artigos. Destes, 57 foram selecionados, sendo a maioria na língua inglesa. Os descritores utilizados, em línguas inglesa, espanhola e portuguesa, foram: (a) aditivos alimentares; (b) aditivos alimentares + tartrazina; (c) corantes alimentares; (d) corantes alimentares + riscos + saúde; e (e) aditivos alimentares + riscos + saúde. 
Os critérios de inclusão de artigos foram: (a) interesse para a saúde pública; (b) efeitos à saúde; e (c) efeitos à saúde infantil.

Foram avaliados estudos descritivos, transversais e experimentais. Os critérios de exclusão foram: (a) estudos sobre a estrutura química dos aditivos; (b) dosagem de resíduos de aditivos em alimentos; e (c) aplicação de aditivos em produtos alimentícios.

Os limites deste estudo se referem às diferenças entre metodologias empregadas e o desenho dos estudos avaliados - dificultando análises comparativas mais aprofundadas, bem como controvérsias nos resultados. Outro aspecto importante é a escassez de estudos sobre outros aditivos alimentares que não os corantes (como os conservadores e os antioxidantes, entre outros), principalmente a tartrazina.

\section{Implicações do consumo de aditivos alimentares e seus riscos à saúde}

\section{O consumo de aditivos alimentares na população infantil}

Ainda são poucos os estudos de consumo de aditivos alimentares, fato de grande importância para avaliação da ingestão e dos possíveis efeitos deletérios que essas substâncias possam causar. Apresentamos em seguida, alguns estudos sobre consumo de aditivos alimentares que utilizaram como método o Questionário de Freqüência Alimentar (QFA) ou Recordatório 24 Horas.

$\mathrm{Na}$ Índia, Rao et al. 12 avaliaram a exposição aos corantes sintéticos em indivíduos de 1 a 5 anos e 6 a 18 anos de idade, de classes sócioeconômicas distintas utilizando QFA. As crianças apresentaram uma ingestão de alimentos sólidos entre 2 e 465g/dia e de 25 a 840mL/dia de alimentos líquidos com adição de corantes. Entre os oito corantes permitidos no país, seis foram consumidos pela população estudada. Para alguns indivíduos a ingestão excedeu a IDA para os corantes tartrazina, amarelo crepúsculo e eritrosina que é de 7,5, 2,5 e 0,1mg/kg de peso corporal, respectivamente. A ingestão média de corantes por pessoa foi de $17,2 \mathrm{mg} / \mathrm{dia}$, sendo a mesma menor do que a observada nos Estados Unidos, onde o consumo foi de $77,1 \mathrm{mg}$. Os autores atribuíram a menor ingestão de corantes na Índia ao baixo consumo de alimentos processados.

No estudo realizado no Kuwait por Husain et al. 13, foi analisada a ingestão de corantes artificiais por crianças de 5 a 14 anos, com base em um inquérito dietético (Recordatório $24 \mathrm{Ho}$ ras). A amostra foi constituída por 3.141 alunos de ambos os sexos, distribuídos em 58 escolas.
Usando-se a técnica da cromatografia líquida de alta eficiência foi determinado o teor de corantes em 344 itens consumidos. Compararam-se com as IDAs recomendadas pela FAO/OMS no sentido de avaliar o potencial de risco associado ao consumo de corantes artificiais. Os resultados indicaram que dos nove corantes permitidos, quatro (tartrazina, amarelo crepúsculo, carmosina, e vermelho brilhante) excederam as IDAs para as crianças de 5 a 8 anos.

Observou-se nos estudos de Husain et al. 13 e Rao et al. 12 que o consumo de determinados corantes excedeu a IDA. Tal fato é relevante, principalmente para a saúde infantil, uma vez que a IDA é uma medida relacionada à massa corpórea e os principais limites hoje conhecidos são determinados, apenas, para populações adultas.

Através do QFA, Nogueira 14 avaliou o consumo de alimentos com corantes por pré-escolares de creches públicas e particulares do Município do Rio de Janeiro. Os produtos mais consumidos foram: balas, doces, gelatinas com sabor, refrigerantes, iogurtes, biscoitos e refrescos, respectivamente. Observaram-se diferenças entre as creches quanto ao tipo de alimentos consumidos. Nas creches particulares, as gelatinas, refrigerantes, iogurtes e biscoitos recheados foram os alimentos que mais se destacaram. Enquanto nas creches públicas, a prevalência de consumo foi maior para refresco em pó, suco em garrafa, balas e doces. Os corantes encontrados nos rótulos desses produtos foram: amarelo crepúsculo (28\%), amarelo tartrazina (27\%), vermelho bordeaux (17\%), azul brilhante (16\%) e corante natural carmin de cochonilha (12\%), respectivamente.

A diferença encontrada no estudo de Nogueira 14 em relação ao consumo de alimentos com aditivos entre as creches (públicas e particulares) provavelmente ocorreu pelo baixo custo destes alimentos, pois pó para refresco, doces, balas e suco em garrafa são produtos mais baratos do que os alimentos que constituem o grupo das creches particulares.

Foi analisada a qualidade dos doces em massa do tipo junino quanto à identidade, por meio da pesquisa de elementos histológicos e corantes orgânicos artificiais, presença de matérias estranhas e rotulagem. Das 15 amostras coletadas no comércio, nove (60\%) foram condenadas devido à presença de corantes orgânicos artificiais, e duas por rotulagem incompatível com a legislação vigente. $\mathrm{O}$ corante amarelo crepúsculo foi encontrado em $23,3 \%$ da amostra, seguido do ponceau 4R (13,3\%) e do amarelo tartrazina (10\%). Segundo os autores, a legislação brasileira não permite a adição de corantes em doce em pasta (Resolução Normativa $n^{\circ}$. 09/78). Dessa forma, o emprego de corantes configurou fraude 15. 
Como as crianças são consumidores em potencial dessas guloseimas, éimprescindível maior vigilância sobre esses produtos. Além disso, os corantes identificados nesses doces pertencem ao grupo Azo, um derivado nitroso reconhecido como uma substância capaz de causar reações alérgicas como asma e urticária, e tem sido alvo de estudos de mutagênese e carcinogênese por produzir amina aromática, e ácido sulfanílico após ser metabolizado pela microflora intestinal. São também denominados compostos azóicos, azoderivados ou azocompostos 16,17.

É inegável sob o ponto de vista tecnológico que os aditivos assumem papel importante na produção de alimentos em larga escala. Porém, deve haver maior preocupação quanto aos riscos toxicológicos provocados pela ingestão diária dessas substâncias.

No Município do Rio de Janeiro, foram coletadas 43 amostras de bebidas não alcoólicas e não gaseificadas (bebidas isotônicas, preparados sólidos para refresco, guaraná natural e xaropes de groselha). Usando-se a técnica de cromatografia líquida de alta eficiência identificaram-se a presença e o tipo de corantes. Foram encontrados os corantes: amaranto (37\%), amarelo crepúsculo $(33 \%)$ e tartrazina (28\%), respectivamente. O amaranto esteve presente em $50 \%$ das amostras do xarope de groselha em concentração acima do teor permitido pela legislação, caracterizando fraude 16,17 . Os autores alertaram para o fato da quantificação do teor de corante ter sido realizada na amostra diluída como indicado no rótulo, porém, alguns consumidores, principalmente as crianças, fazem uso desse produto muitas vezes na forma concentrada, como em coberturas para sorvetes e bolos 18 .

No estudo de Alves et al. 18, a situação é bastante preocupante, pois as bebidas não alcoólicas apresentaram concentrações de corantes artificiais acima do permitido por lei. Além de se configurar uma fraude, ainda há o risco dessas substâncias provocarem reações adversas como alergia, devendo ser controlado o seu uso.

\section{A relação entre aditivos alimentares} e neoplasias

As neoplasias malignas representam um grave problema de Saúde Pública e diversos estudos têm associado o aparecimento do câncer a hábitos e estilos de vida não saudáveis, destacando-se o consumo de tabaco, bebidas alcoólicas, dieta rica em gorduras trans e saturadas, nitratos e nitritos, e a baixa ingestão de fibras 19,20,21,22.

Estudos epidemiológicos têm apontado a relação entre a exposição a determinadas substâncias (nitratos e outros aditivos alimentares) en- contradas na dieta humana e o desenvolvimento de câncer específico, tais como o de estômago, esôfago, cólon, reto, mama e ovário 23,24,25,26.

É pertinente a constante preocupação com as substâncias químicas sintéticas, pois estas podem desencadear o câncer, estando presentes nos alimentos como aditivos ou contaminantes ambientais de uso na agricultura como, por exemplo, os agrotóxicos. Também novas substâncias podem ser formadas durante a cocção ou através do processo de conservação de alimentos a partir do emprego de técnicas como a defumação e a salmoura. A capacidade que essas substâncias apresentam de induzir danos celulares e mutação no DNA podem ser minimizadas pelo sistema de defesa natural, tanto quanto por um eficiente sistema de desintoxicação celular e reparação do DNA produzidos pelos organismos animal e humano, em condições favoráveis 2 .

O interesse na identificação de substâncias dietéticas específicas responsáveis pelo desenvolvimento do câncer é compreensível, porém, não deve ser visto de forma isolada, pois há que considerar a multiplicidade de fatores intervenientes no processo de mutações, hiperplasias, inibição da integração celular, ativação oncogênica, desativação dos genes supressores de tumor, expansão clonal e progressão do tumor 25,26,27.

As nitrosaminas e os antioxidantes BHA (antioxidante butil hidroxianisol) podem provocar danos e mutações no DNA, provavelmente desencadeando, desta forma, a neoplasia. Também alguns corantes artificiais, nomeadamente a eritrosina e a tartrazina, apresentam potencial carcinogênico 25,26. Essas substâncias alteram o "turn-over" das células durante o seu crescimento normal ou no processo de hiperplasia regenerativa e, deste modo, contribuem para a incidência de câncer 26 .

A identificação de agentes antimutagênicos e/ou anticarcinogênicos em alimentos é de grande relevância na busca de estratégias para a prevenção do câncer. Atualmente, os corantes mais investigados são os do grupo Azo (amarelo tartrazina, amarelo crepúsculo e vermelho 40). Isso se deve aos possíveis efeitos mutagênicos e carcinogênicos desses corantes 27 .

Na França, avaliou-se a segurança do consumo do corante tartrazina a partir de uma revisão sistemática de estudos experimentais. O consumo teórico máximo estimado de tartrazina foi de $14,5 \%$ e $37,2 \%$ da IDA $(7,5 \mathrm{mg} / \mathrm{kg}$ de peso corporal) para adultos e crianças, respectivamente. Quanto à associação do consumo de tartrazina e efeitos adversos à saúde, os autores acreditam que a mesma é superestimada, e os mecanismos patogênicos ainda não foram suficientemente 
compreendidos 28. Os autores chamam a atenção para alimentos como sorvetes, sobremesas, bolos e produtos de confeitaria que apresentam tartrazina e que são comercializados sem a devida rotulagem. Nesse caso, o consumo desses produtos pode se configurar num risco.

Foram investigados os efeitos do uso prolongado do corante tartrazina na mucosa gástrica de ratos. O referido corante é um dos mais utilizados no mundo para colorir alimentos. Observou-se aumento significativo na produção de linfócitos e eosinófilos na mucosa do antro gástrico dos ratos. Não ocorreram alterações carcinogênicas em nenhuma das regiões gástricas com a dose e o tempo utilizados $(7,5 \mathrm{mg}$ de tartrazina $/ \mathrm{kg} / \mathrm{dia}$ durante dez meses), respectivamente. Como medida de segurança, os autores sugerem outros estudos modificando-se a dose e tempo de exposição ao corante tartrazina, de forma a permitir a observação dos efeitos associados a outros carcinógenos 2 .

No estudo realizado por Abdel-Aziz et al. 29, foi avaliado o efeito do corante eritrosina na reprodução dos camundongos machos investigando sua influência na espermatogênese. Os resultados apontaram redução significativa da atividade testicular da enzima LDH-X (isoenzima dehidrogenase láctica) no grupo de camundongos exposto ao corante eritrosina (na dose de $18 \mathrm{mg} / \mathrm{kg}$ durante 21 dias consecutivos). A administração do referido corante para o mesmo intervalo de tempo nas doses de 68 e de $136 \mathrm{mg} / \mathrm{kg}$ acentuou ainda mais a redução da enzima (LDH$\mathrm{X})$. Observou-se redução nos níveis de espermatozóides entre os camundongos que receberam eritrosina por 21 dias consecutivos nas doses de $68 \mathrm{mg} / \mathrm{kg}^{-1}$ para $50,8 \%$ e de $136 \mathrm{mg} / \mathrm{kg}^{-1}$ para $33,9 \%$. Além disso, a mobilidade dos espermatozóides mostrou diminuição significativa após consumo do corante nas doses de 68 e de 136mg/ $\mathrm{kg}^{-1}$ para $57 \%$ e $80,5 \%$, respectivamente. A incidência de espermatozóides com cabeças anormais no grupo controle foi de $19,83 \%$, e de $57,1 \%$ e $64,7 \%$ nos grupos que receberam doses de 68 e de $136 \mathrm{mg} / \mathrm{kg}^{-1}$, respectivamente. Nesse estudo, o corante eritrosina desencadeou ação tóxica em células germinativas dos camundongos machos interferindo de forma significativa na espermatogênese.

No Japão, foram analisados a percepção e o nível de conhecimento sobre fatores de riscos ambientais e genéticos associados à prevenção do câncer. Participaram do estudo 1.355 japoneses (609 homens e 746 mulheres), com 20 ou mais anos de idade. Selecionaram-se 12 fatores de riscos (bebidas alcoólicas, dieta inadequada, aditivos alimentares e agrotóxicos, consumo de carnes e peixes defumados, tabagismo, obesidade, inativi- dade física, exposição ocupacional, infecções viral e bacteriana, e estresse). Foram considerados como fatores de risco para câncer as infecções virais e bacterianas (51\%), seguidas pelo hábito de fumar $(43 \%)$, estresse (39\%), aditivos alimentares $(37 \%)$, consumo de carnes e peixes defumados (21\%) e bebida alcoólica (22\%). A fração atribuída à especulação do câncer como uma doença adquirida geneticamente foi $32 \%$, enquanto que $36 \%$ das pessoas relataram ser o câncer uma doença que se pode prevenir desde que sejam desenvolvidas melhorias no estilo de vida 30 .

Na Espanha, García et al. 31 analisaram o comportamento e a percepção em relação às medidas para redução de câncer. Foram utilizados dados da pesquisa longitudinal intitulada Cornella Health Interview Survey Follow-up Study, sendo então avaliados 1.438 indivíduos (668 homens e 770 mulheres) que em 2002 responderam perguntas sobre percepção de risco associada ao estilo de vida e câncer. O estudo revelou que $95,8 \%$ dos indivíduos acreditavam que abolir o hábito de fumar, 94,9\% evitar exposição ao sol, e 81\% evitar o consumo de bebidas alcoólicas eram medidas de proteção contra o câncer. Já o contato com campos eletromagnéticos (92,1\%), o consumo de alimentos com corantes e outros aditivos $(78,4 \%)$ ou pesticidas $(69,4 \%)$ foram destacados como fatores de risco. Ainda no mesmo estudo, comparando-se os sexos, as mulheres apontaram mais freqüentemente comportamentos de saúde e fatores ambientais como os responsáveis pelo aparecimento do câncer. O nível de escolaridade influenciou na percepção de risco em relação aos fatores dietéticos. Quanto aos aditivos, 85,7\% dos indivíduos com menor escolaridade e $72,3 \%$ dos indivíduos com maior escolaridade consideraram benéfico evitar o consumo desses produtos, respectivamente.

Observou-se no estudo realizado por Garcia et al. 31 que o emprego de novas tecnologias pelas indústrias foi legitimado pelos indivíduos com maior nível de instrução, ou seja, eles não perceberam os possíveis riscos à saúde advindos do consumo de alimentos com aditivos. Tal fato chama atenção para a necessidade de aperfeiçoamento das estratégias de comunicação de risco para doenças como o câncer como elemento importante de promoção da saúde.

No Japão, com base na técnica do ensaio cometa, foram avaliados se os aditivos alimentares mais consumidos no país induziam danos no DNA dos ratos. A administração dos aditivos foi oral em até $0,5 \times \mathrm{LD}_{50}$ ou na dose limite de $2.000 \mathrm{mg} / \mathrm{kg}$. O estudo demonstrou danos no DNA em órgãos de ratos provocados por alguns aditivos. O corante tartrazina na dose $\geq 10 \mathrm{mg} / \mathrm{kg}$ induziu a danos no DNA do estomago e cólon. 
Já o amaranto $(100 \mathrm{mg} / \mathrm{kg})$, provocou danos no DNA da bexiga. Os corantes: amarelo crepúsculo, azul brilhante e carmin não acarretaram danos estatisticamente significativos 32 .

Ainda no mesmo estudo ${ }^{32}$, os aditivos conservadores (derivados do ácido benzóico e o nitrato de sódio) não provocaram danos no DNA. Já os antioxidantes BHA e butil hidroxitolueno (BHT) induziram danos no DNA do estômago, cólon, bexiga e cérebro. Sendo que as doses mais baixas para indução de danos no DNA do cólon foram $500 \mathrm{mg} / \mathrm{kg}$ para o BHA e $100 \mathrm{mg} / \mathrm{kg}$ para o BHT. Apesar do referido estudo ter sido realizado com doses elevadas de aditivos, o consumo desenfreado dos mesmos pode ultrapassar a IDA recomendada pelo JECFA acarretando sérios riscos à saúde.

A relação entre aditivos alimentares e transtorno de déficit de atenção com hiperatividade

Nas últimas décadas, o estudo sobre o transtorno do déficit de atenção e hiperatividade tem atraído pesquisadores da área da medicina, psicologia, nutrição e educação. Esse interesse é fruto do aumento do número de casos de crianças com esse distúrbio, sendo a prevalência de $3 \%$ a $5 \%$ em crianças em idade escolar. A criança que apresenta o transtorno do déficit de atenção e hiperatividade normalmente persiste com os sintomas em grande parte de sua juventude e também na vida adulta. $\mathrm{O}$ impacto desse distúrbio sobre a qualidade de vida é marcante, não apenas para a criança hiperativa, como também para toda sua família 33,34,35

A Associação Americana de Psiquiatria [American Psychiatric Association-APA] 35 define, pelo Manual Diagnóstico e Estatístico de Transtornos Mentais, DSM-IV (1994), o transtorno de déficit de atenção e hiperatividade como um distúrbio com sinais de falta de atenção e impulsividade, não adequados ao nível de desenvolvimento respectivo. Designa-se esse distúrbio por déficit de atenção, uma vez que as dificuldades de atenção são proeminentes e estão sempre presentes nas crianças com este diagnóstico. Embora o excesso de atividade motora diminua freqüentemente na adolescência, muitas vezes as dificuldades de atenção permanecem.

A desatenção pode manifestar-se em situações escolares, profissionais ou sociais. Os indivíduos com esse transtorno podem não prestar muita atenção a detalhes ou podem cometer erros por falta de cuidados nos trabalhos escolares ou em outras tarefas 36 .

A Classificação Internacional das Doenças (CID-10), da OMS, classifica hiperatividade in- fantil por: “...início precoce; uma combinação de comportamento hiperativo e pobremente modulado, com desatenção marcante e falta de envolvimento persistente nas tarefas; conduta evasiva nas situações; e persistência no tempo dessas características de comportamento".

As características sintomatológicas do transtorno do déficit de atenção e hiperatividade podem persistir na vida adulta em até $50 \%$. Na maioria dos casos, há significativa melhora do quadro do transtorno na adolescência, talvez devido ao aumento das monoaminas em conseqüência do acréscimo no nível de hormônios sexuais 37,38 .

Estudos longitudinais epidemiológicos têm demonstrado que crianças com comportamento hiperativo, quando não adequadamente tratadas, ficam mais propensas a desenvolver distúrbios sociais, emocionais e comportamentais, bem como a ter problemas na escola 37,38 .

Em 1975, Feingold 39 publicou um livro intitulado Why Your Child Is Hyiperactive? A referida obra deu início à discussão sobre a função dos aditivos como desencadeadores da hiperatividade em crianças. O estudo analisou, por meio de dieta de exclusão, o comportamento de crianças após a retirada de aditivos alimentares, nomeadamente os corantes e conservadores artificiais. Feingold 39 constatou que $30 \%$ a $50 \%$ das crianças, que haviam sido submetidas à dieta, apresentaram melhora no comportamento hiperativo.

Após o trabalho de Feingold 39, poucos estudos puderam apoiar sua hipótese, por razões metodológicas, visto tratar-se de um estudo não controlado, no qual não foram utilizados scores padronizados para interpretação de comportamentos e também não se monitorizou as crianças quanto ao seguimento da dieta de exclusão de aditivos.

O estudo realizado por Boris \& Mandel 38 mostrou o papel dos corantes e conservadores artificiais no aparecimento do transtorno do déficit de atenção e hiperatividade. Através de uma dieta de exclusão, os sintomas desapareceram. Crianças atópicas com transtorno do déficit de atenção e hiperatividade tiveram uma resposta benéfica mais significativa com a dieta de eliminação do que as crianças não atópicas. Testes de exclusão e reposição, após uma controlada dieta de eliminação, podem auxiliar na identificação dos fatores que determinam o transtorno do déficit de atenção e hiperatividade.

Entre os corantes considerados responsáveis por alterações no comportamento humano destacam-se: tartrazina, amaranto, vermelho ponceau, eritrosina, caramelo amoniacal. No que se refere aos conservadores, os derivados do ácido benzóico e os ácidos sulfídrico e sulfito podem 
induzir à hiperatividade. Os antioxidantes sintéticos também são considerados fatores de risco para o transtorno do déficit de atenção e hiperatividade 39,40,41.

Tanaka 42 avaliou o efeito reprodutivo e neurocomportamental do corante tartrazina em ratos. O referido corante foi acrescentado à dieta para fornecer níveis de $0 \%$ (controle), $0,05 \%$, $0,15 \%$ e $0,45 \%(83,259,773 \mathrm{mg} / \mathrm{kg} / \mathrm{dia}$, respectivamente) em ratos com cinco semanas de idade (geração F0) e nove semanas de idade (geração F1). O estudo evidenciou o seguinte: a atividade motora foi mais intensa nos ratos machos e mais jovens, com a administração de $259 \mathrm{mg} / \mathrm{kg} /$ dia. Não foi observado nenhum efeito adverso da tartrazina em relação à reprodução (tamanho da ninhada, peso da ninhada e relação do sexo ao nascimento). Alguns efeitos adversos ocorreram nos parâmetros neurocomportamentais durante o período de lactação dos ratos. Para Tanaka ${ }^{42}$, esse fato aconteceu porque a quantidade estava muito acima da IDA de tartrazina $(0-7,5 \mathrm{mg} / \mathrm{kg} /$ dia), e o consumo dietético real deste aditivo parece ser muito mais baixo, conseqüentemente, não produziriam os efeitos adversos nos seres humanos.

É pertinente traçar alguns comentários em relação ao estudo apresentado por Tanaka 42, pois a hiperatividade foi mais freqüente nos ratos machos, fenômeno também observado em crianças do sexo masculino. Além disso, o consumo mais elevado de guloseimas (doces, balas, sorvetes, gelatinas e refrigerantes) por crianças pode ultrapassar a IDA para o corante tartrazina, como foi demonstrado também no estudo de Husain et al. 13 .

Há ainda muitas incertezas sobre o papel dos aditivos alimentares, destacando-se, entre eles, os corantes artificiais como os responsáveis pelo aparecimento do transtorno do déficit de atenção e hiperatividade. Alguns estudos demonstraram melhora no quadro clínico da hiperatividade em crianças submetidas a uma dieta isenta dessas substâncias, mas é preciso aprofundar um pouco mais os estudos na área para que a criança não seja submetida a uma dieta de exclusão de aditivos muito rigorosa $43,44,45$.

\section{A relação entre os aditivos e hipersensibilidade alimentar}

Os fatores de risco para o desenvolvimento de enfermidades atópicas são multifatoriais, destacando-se como relevantes à predisposição genética, a exposição precoce a substâncias alergênicas e redução da imunidade. Várias estratégias podem ser implementadas no sentido de reduzir a incidência da hipersensibilidade, como: evitar sensibilização intra-uterina, tabagismo, exclusão de alimentos alergênicos e aditivos alimentares principalmente durante a lactação e no primeiro ano de vida da criança $44,45,46$.

Os corantes artificiais podem desencadear hipersensibilidade. O corante amarelo tartrazina é encontrado em inúmeros alimentos. Sua estrutura química se assemelha aos benzoatos, salicilatos e indometacina, daí a possibilidade de reações alérgicas cruzadas entre fármacos. Além disso, a tartrazina pode desencadear hipercinesia em pacientes hiperativos e eosinofilia. A ocorrência de púrpura não-trombocitopatogênica não é comum, mas significa que a tartrazina pode inibir a agregação plaquetária, à semelhança dos salicilatos, benzoato de sódio e metabissulfito de sódio $47,48,49$.

A hipersensibilidade à tartrazina ocorre em $0,6 \%$ a $2,9 \%$ da população, com incidência maior nos indivíduos atópicos ou com intolerância aos salicilatos. As manifestações clínicas mais comuns são: urticária, broncoespasmo, rinite e angioedema 43 .

Devido à comprovação dos efeitos adversos provocados pelo corante tartrazina, a Agência Nacional de Vigilância Sanitária (ANVISA), por meio da Resolução RE $n^{o} .572$ de 5 de abril de 2002, obriga os fabricantes a destacar a advertência na bula e na embalagem dos medicamentos que contêm este corante.

O corante amarelo crepúsculo também pode provocar reações anafilactóides causando angioedema, choque anafilático, vasculite e púrpura. Pode ocorrer reação cruzada entre o amarelo crepúsculo, paracetamol, ácido acetilsalisílico, benzoato de sódio e outros corantes do grupo Azo 45,48.

Alguns aditivos alimentares podem induzir à urticária e angioedema em indivíduos suscetíveis. Em estudo duplo-cego realizado por MontañoGarcía \& Orea-Solano 46, com 33 pacientes com diagnóstico de urticária e angioedema crônicos e história clínica que sugeriam relação entre o aparecimento dos sintomas e a ingestão de aditivos alimentares, ou sem causa desencadeante definida, realizaram-se testes com os seguintes aditivos: metabissulfito de sódio, benzoato de sódio e corante tartrazina. Nesse estudo, 30,3\% dos pacientes apresentaram reação positiva a um ou mais aditivos. Dos 132 testes, 8,3\% foram positivos para angioedema e urticária, sendo $15 \%$ ao benzoato de sódio, 12,1\% à tartrazina e $6 \%$ ao metabissulfito, respectivamente.

Numa fábrica de corantes naturais da Espanha, Tabar et al. 49,50 investigaram a incidência de sensibilização e asma ocupacional provocada pelo corante carmin (cochonilha). Dos trabalhadores expostos ao corante carmin, $48,1 \%$ 
apresentaram sensibilização e 18,5\% asma ocupacional, respectivamente. A asma ocupacional ocorreu devido à inalação de certas partículas protéicas de artrópodes (cochonilhas), que por sua vez atuaram como aeroalérgenos. Para os autores, o carmin é um agente capaz de produzir asma ocupacional, cujo mecanismo, seria imunológico mediado por anticorpos IgE. Além disso, por se tratar de um corante amplamente utilizado como aditivo alimentar, como excipiente farmacêutico e na composição de numerosos cosméticos, este pode se constituir como causa de diversas reações alérgicas, tanto por sua ingestão como por contato cutâneo direto.

Foi realizado um estudo retrospectivo baseado na análise dos dados de pacientes que relataram episódios de urticária e/ou angioedema após a ingestão de alimentos com corante tartrazina. Os pacientes foram submetidos ao teste IgE para os alérgenos mais comuns por via inalatória e alérgenos alimentares, e um duplo-cego placebo-controlado (DBPC) para avaliar a exposição ao corante tartrazina. Dos 102 indivíduos que participaram do estudo, 18,6\% mostraram pelo menos uma reação positiva relevante para o teste IgE para alimentos alergênicos. Somente $1 \%$ apresentou reações após a ingestão de $5 \mathrm{mg}$ de tartrazina. Esse estudo apontou uma baixa freqüência de urticária e/ou angioedema agudos induzidos pelo corante tartrazina 51 .

No estudo de meta-análise, Ram \& Ardem 52 avaliaram o efeito tartrazina (exclusão ou desafio) na manifestação da asma. Foram considerados estudos com a administração oral da tartrazina (desafio) contra o placebo, ou da exclusão dietética da tartrazina contra dieta normal. Incluíramse os estudos que focalizaram asma alérgica em adultos e crianças. Dos 90 resumos encontrados, apenas 18 foram considerados relevantes. Destes, seis estudos atendiam aos critérios de inclusão, mas somente três apresentaram resultados em um formato que permitisse a análise dentro dos pressupostos da meta-análise. Em nenhum dos estudos o desafio da tartrazina ou a exclusão de tartrazina da dieta alterou significativamente os resultados da asma. Segundo os autores, não foi possível fornecer conclusões concretas a respeito dos efeitos da tartrazina no desencadeamento da asma, devido à insuficiência de evidências sobre o tema.

Foi investigada a produção de leucotrienos em pacientes com dermatite atópica utilizando-se aditivos alimentares. O estudo DBPC foi conduzido usando-se os seguintes aditivos: corante tartrazina, conservador benzoato de sódio e nitrito. Participaram do estudo 28 indivíduos em três grupos diferentes (A, B, C). O grupo A representou os indivíduos não-atópicos $(\mathrm{n}=10)$.
Os grupos $\mathrm{B}$ e C foram constituídos por pacientes com história de dermatite atópica. Quanto ao gênero, 11 eram do sexo feminino e 7 do masculino, a média de idade foi de 29 anos. Os aditivos foram oferecidos em cápsulas para teste de provocação DBPC, em uma única administração do desafio. A ordem foi randomizada e o tempo de observação foi de 48 horas após cada provocação; o status da pele foi registrado antes e depois de cada teste. As respostas foram positivas para todos os aditivos investigados. $\mathrm{O}$ aumento de leucotrienos na presença de apenas um aditivo alimentar foi observada na maioria dos pacientes com intolerância comprovada pelo DBPC aos alimentos e à tartrazina, benzoato e nitrito. O estudo concluiu que os aditivos alimentares isoladamente podem agravar ou desencadear dermatite em pacientes atópicos por meio do aumento na produção de leucotrienos 53 .

Avaliou-se a produção de metabólitos urinários de histamina e leucotrienos em vinte pacientes com história de urticária crônica. Foram selecionados para o desafio DBPC com ácido acetilsalisílico (AAS) e aditivos alimentares. Dez pacientes (grupo B) foram negativos para ambos os desafios. Dez pacientes (grupo C) apresentaram urticária e/ou angioedema durante ou 24 horas após o desafio, com reações a AAS (cinco pacientes) ou a aditivos alimentares (cinco pacientes). O grupo controle foi constituído por 15 voluntários saudáveis (grupo A). Os pacientes nos grupos B e C foram desafiados duas vezes: com placebo (como os grupos $\mathrm{B} 1 \mathrm{e} \mathrm{C1}$ ) e com AAS (B2 e C2) ou aditivos alimentares (C2). Quatro amostras de urina foram coletadas; uma durante a noite antes do desafio específico, e três em 2, 6 e 24 horas após o desafio. O estudo evidenciou uma variação significativa na excreção urinária de metil-histamina no grupo $\mathrm{C} 2$ depois de 2, 6 e 24 horas. Após o desafio específico, somente os pacientes $\mathrm{C} 2$ apresentaram aumento elevado na excreção urinária de leucotrienos. Os resultados mostraram que a excreção urinária de metil-histamina e de leucotrienos foi maior em pacientes com urticária crônica devido ao AAS ou à hipersensibilidade ao aditivo alimentar após o desafio 54 .

Inomata et al. 55 relataram o caso de uma menina de cinco anos que apresentava quadros episódicos de urticária, angioedema, cefaléia, dispnéia, perda da consciência e dor abdominal. Por meio de anamnese alimentar contatou-se que os referidos sintomas ocorriam após a ingestão de doces coloridos, tais como balas e jujubas. Foram realizados testes de desafio com aditivos alimentares e drogas antiinflamatórias não-esteróides após a eliminação desses itens. O prick-test foi feito com aditivos e drogas antiinflamatórias 
não-esteróides. Foi constatada intolerância aos corantes do grupo azo e aos antiinflamatórios não-esteróides. Para os autores, esse resultado sugere que a sensibilidade química múltipla a aditivos alimentares e drogas que contenham tinturas azo em crianças pode ser importante para o diagnóstico da hipersensibilidade.

Outro estudo de caso de uma mulher com 44 anos e história de urticária crônica e de rinite persistente. Seus sintomas respondiam bem à administração de anti-histamínico. Foram realizados os prick-test com diversos alérgenos, dentre eles, os alimentares, e os resultados foram todos negativos. Nos exames bioquímicos foi encontrada uma discreta eosinofilia (5\%). Após melhora do quadro de rinite e urticária recomendou-se dieta de exclusão e o desafio DBPC com aditivos alimentares. Todos os aditivos foram administrados em cápsulas numa seqüência randomizada. Foram usadas nos desafios oito substâncias ativas e quatro placebos com intervalos de uma semana. A paciente foi controlada por duas horas depois de cada desafio. Obtiveram-se os seguintes resultados: após 30 minutos da ingestão de 10mg do antioxidante butil hidroxianisol foi desencadeada rinite severa, desaparecendo os sintomas 30 minutos após a administração de anti-histamínico. Similarmente, a rinite severa foi constatada quatro horas depois da ingestão de $25 \mathrm{mg}$ do conservador metabissulfito de sódio; os sintomas foram controlados também com anti-histamínico. A urticária severa desencadeou-se 45 minutos após a ingestão de 100mg do realçador de sabor glutamato monossódico. Novamente foi observado o quadro de rinite severa, 30 minutos e quatro horas depois da administração de $10 \mathrm{mg}$ do butil hidroxitolueno e $25 \mathrm{mg}$ do metabisulfito de sódio, respectivamente, e seguido de urticária em 45 minutos à administração de 100mg de glutamato monossódico. Nenhuma reação foi induzida pelas cápsulas do placebo 56 .

O estudo de Asero 56 demonstrou que embora a intolerância ao aditivo alimentar raramente represente a causa primária da urticária crônica, o mesmo pode potencializar a urticária idiopática subjacente como foi o caso da referida paciente, cujo quadro foi agravado pelo glutamato monossódico.

Outros estudos também apontaram os efeitos adversos desencadeados pelo consumo de aditivos, principalmente os corantes e conservadores, em relação a manifestações de asma, urticária e angioedema 57,58 .

A Tabela 1 sumariza os principais estudos aqui apresentados, destacando-se a populaçãoalvo, o tipo de estudo, aditivos alimentares investigados e resultados obtidos.

\section{Considerações finais}

O comportamento alimentar dos indivíduos corresponde não só aos hábitos alimentares, mas também às práticas de seleção, aquisição, conservação e preparo relativas à alimentação. Tem suas bases na infância, transmitidas pela família e sustentadas pelas tradições, crenças e tabus que passam de geração em geração.

Nas últimas décadas, com o acelerado processo de urbanização vem ocorrendo mudanças no modo de vida das famílias e nos hábitos alimentares. A participação das mulheres no mercado de trabalho, reduzindo a disponibilidade de tempo para o cuidado da alimentação da família, maior acesso a uma enorme variedade de alimentos industrializados de fácil preparo e rápido consumo têm contribuído para essas mudanças 59 .

Atualmente, vem se observando que paralelamente ao consumo dos alimentos básicos há a introdução de produtos industrializados, a partir do estímulo do marketing das indústrias, com destaque para o consumo de macarrão instantâneo, achocolatados, iogurtes, biscoitos recheados, biscoitos salgados e refrescos. Os anúncios de televisão estimulam a compra de certos alimentos normalmente de alta densidade energética (sacarose e gorduras trans e saturadas) e de baixo valor nutritivo 59 . Além disso, grande parte desses produtos contém aditivos alimentares, principalmente corantes, conservadores e antioxidantes artificiais, que podem trazer riscos à saúde.

Apesar dos escassos estudos sobre consumo de aditivos e efeitos à saúde coletiva, em particular à saúde infantil, a nossa revisão sistemática da literatura apontou a criança como um consumidor potencial de alimentos com aditivos alimentares, nomeadamente corantes artificiais. Também demonstrou que o corante tartrazina tem sido o mais investigado aparecendo em $84,6 \%$ dos estudos, sendo avaliado de forma isolada em $45,6 \%$ deles. O corante tartrazina é o mais utilizado na indústria de alimentos e medicamentos, portanto, se justifica o grande número de estudos sobre o mesmo. Merece destaque aqui, que outros corantes do grupo Azo como o amarelo crepúsculo e vermelho 40 , além dos aditivos conservadores e antioxidantes, também podem provocar efeitos deletérios, sendo pertinente a elaboração de mais pesquisas.

Em relação aos resultados dos estudos associando o consumo de aditivos ao aparecimento do câncer, identificaram-se divergências. Os efeitos adversos à saúde foram observados, principalmente nos estudos em que a IDA foi muito elevada. Poucos trabalhos investigaram o trans- 
Tabela 1

Estudos incluídos na revisão sistemática da literatura no período de 1988-2007.

\begin{tabular}{|c|c|c|c|c|c|}
\hline Autores & Ano & $\begin{array}{c}\text { População/ } \\
\text { Tipo de estudo }\end{array}$ & $\begin{array}{l}\text { Objetivos do } \\
\text { estudo }\end{array}$ & $\begin{array}{l}\text { Aditivos } \\
\text { alimentares }\end{array}$ & Conclusão \\
\hline Worm et al. 53 & 2001 & $\begin{array}{l}\text { Adultos (28) } \\
\text { Estudo DBPC }\end{array}$ & $\begin{array}{c}\text { Avaliar aumento de } \\
\text { leucotrienos em pacientes } \\
\text { com dermatite atópica }\end{array}$ & $\begin{array}{c}\text { Tartrazina, benzoato de } \\
\text { sódio, nitrito }\end{array}$ & $\begin{array}{c}\uparrow \text { de leucotrienos na } \\
\text { presença dos aditivos. Os } \\
\text { aditivos podem agravar } \\
\text { ou desencadear dermatite } \\
\text { atópica }\end{array}$ \\
\hline $\begin{array}{l}\text { Di Lorenzo } \\
\text { et al. } 54\end{array}$ & 2002 & $\begin{array}{l}\text { Adultos (20) } \\
\text { Estudo DBPC }\end{array}$ & $\begin{array}{l}\text { Avaliar a produção de } \\
\text { metabólitos urinários de } \\
\text { histamina e leucotrienos por } \\
\text { meio de DBPC com AAS e } \\
\text { aditivos alimentares }\end{array}$ & $\begin{array}{c}\text { Tartrazina, eritrosina, } \\
\text { benzoato de sódio, } \\
\text { metabissulfito, glutamato } \\
\text { monossódico }\end{array}$ & $\begin{array}{l}\text { 个 na excreção urinária de } \\
\text { leucotrienos e metil-xantina } \\
\text { nos pacientes com urticária }\end{array}$ \\
\hline Sasaki et al. 32 & 2002 & $\begin{array}{l}\text { Estudo experimental } \\
\text { (ratos Wistar) }\end{array}$ & $\begin{array}{c}\text { Analisar os danos no } \\
\text { DNA acarretados pelo } \\
\text { consumo dos aditivos } \\
\text { (corantes, conservadores, } \\
\text { antioxidantes) por meio do } \\
\text { ensaio cometa; com dose } \\
0,5 \times \text { LD50 }\end{array}$ & $\begin{array}{c}\text { Tartrazina, amaranto, } \\
\text { amarelo crepúsculo, azul } \\
\text { brilhante, carmin, } \mathrm{BHT}, \mathrm{BHA} \text {, } \\
\text { acido benzóico, nitrato de } \\
\text { sódio }\end{array}$ & $\begin{array}{c}\text { Induziram danos no DNA: } \\
\text { Tartrazina } \geq 10 \mathrm{mg} / \mathrm{kg} \\
\text { (estomago e colon); } \\
\text { Amaranto } 100 \mathrm{mg} / \mathrm{kg} \\
\text { (bexiga); BHT } 100 \mathrm{mg} / \mathrm{kg} \text { e } \\
\text { BHA } 500 \mathrm{mg} / \mathrm{kg} \text { (bexiga e } \\
\text { cólon). Os demais aditivos } \\
\text { não provocaram danos } \\
\text { significativos }\end{array}$ \\
\hline Nettis et al. 51 & 2003 & $\begin{array}{c}\text { Estudo retrospectivo } \\
\text { baseado em dados de } \\
\text { pacientes (102) com urticária } \\
\text { e/ou angioedema. Teste IgE } \\
\text { para alérgenos comuns, e } \\
\text { desafio DBPC }\end{array}$ & $\begin{array}{c}\text { Avaliar a exposição ao } \\
\text { corante tartrazina no } \\
\text { desencadeamento da asma } \\
\text { e/ou angioedema }\end{array}$ & Corante tartrazina & $\begin{array}{c}\text { O estudo revelou } \downarrow \\
\text { freqüência de urticária e/ou } \\
\text { angioedema provocadas } \\
\text { pela tartrazina }\end{array}$ \\
\hline Rao et al. 12 & 2004 & $\begin{array}{c}\text { Crianças de } 1 \text { a } 5 \text { anos e de } \\
6 \text { a } 18 \text { anos/Índia }\end{array}$ & $\begin{array}{c}\text { Avaliar o consumo de } \\
\text { aditivos usando-se QFA }\end{array}$ & $\begin{array}{l}\text { Tartrazina, amarelo } \\
\text { crepúsculo, eritrosina, } \\
\text { vermelho ponceau, } \\
\text { carmosina, azul brilhante }\end{array}$ & $\begin{array}{c}\text { Dos } 8 \text { corantes permitidos } \\
\text { na Índia, } 6 \text { foram } \\
\text { consumidos. A IDA excedeu } \\
\text { para os corantes tartrazina, } \\
\text { amarelo crepúsculo e } \\
\text { eritrosina }\end{array}$ \\
\hline García et al. 31 & 2005 & Adultos (1.438)/Espanha & $\begin{array}{c}\text { Analisar a percepção e } \\
\text { comportamento em relação } \\
\text { às medidas para redução } \\
\text { do câncer }\end{array}$ & $\begin{array}{l}\text { Tabagismo, exposição a } \\
\text { campos eletromagnéticos, } \\
\text { exposição ao sol, etilismo, } \\
\text { consumo de aditivos }\end{array}$ & $\begin{array}{c}\text { Medidas para evitar o } \\
\text { câncer: não fumar (95,8\%), } \\
\text { não se expor ao sol (94,9\%), } \\
\text { não se expor a campos } \\
\text { magnéticos }(92,1 \%), \text { não } \\
\text { consumir bebida alcoólica } \\
\text { (81\%), não consumir aditivos } \\
\text { alimentares (78,4\%), evitar } \\
\text { alimentos com agrotóxicos } \\
(69,4 \%)\end{array}$ \\
\hline
\end{tabular}

(continua) 
Tabela 1 (continuação)

\begin{tabular}{|c|c|c|c|c|c|}
\hline Autores & Ano & $\begin{array}{l}\text { População/ } \\
\text { Tipo de estudo }\end{array}$ & $\begin{array}{l}\text { Objetivos do } \\
\text { estudo }\end{array}$ & $\begin{array}{c}\text { Aditivos } \\
\text { alimentares }\end{array}$ & Conclusão \\
\hline Husain et al. 13 & 2006 & $\begin{array}{c}\text { Crianças de } 5 \text { a } 14 \text { anos/ } \\
\text { Kuaite }\end{array}$ & $\begin{array}{c}\text { Avaliar o consumo de } \\
\text { corantes (Recordatório } \\
24 \text { horas) }\end{array}$ & $\begin{array}{c}\text { Tartrazina, amarelo } \\
\text { crepúsculo, carmosina, } \\
\text { vermelho } 40 \text {, ponceau, azul } \\
\text { brilhante }\end{array}$ & $\begin{array}{l}\text { Dos } 9 \text { corantes permitidos, } \\
4 \text { excederam as IDAs para } \\
\text { crianças de } 2 \text { a } 8 \text { anos }\end{array}$ \\
\hline Freitas et al. 15 & 2006 & $\begin{array}{l}\text { Doces do tipo junino/ } \\
\text { Rio de Janeiro }\end{array}$ & $\begin{array}{c}\text { Analisar o teor e tipo de } \\
\text { corantes artificiais em doce } \\
\text { em pasta }\end{array}$ & $\begin{array}{l}\text { Tartrazina, amarelo } \\
\text { crepúsculo, vermelho } \\
\text { ponceau }\end{array}$ & $\begin{array}{l}\text { Corantes mais encontrados: } \\
\text { amarelo crepúsculo }(23,3 \%) ; \\
\text { vermelho ponceau }(13,3 \%) ; \\
\text { tartrazina }(10 \%)\end{array}$ \\
\hline Inoue et al. 30 & 2006 & Adultos (1.355)/Japão & $\begin{array}{l}\text { Analisar a percepção e o } \\
\text { nível de conhecimento } \\
\text { para vários fatores de riscos } \\
\text { ambientais e genéticos para } \\
\text { câncer }\end{array}$ & $\begin{array}{l}\text { Bebidas alcoólicas, dieta } \\
\text { inadequada, tabagismo, } \\
\text { consumo de aditivos e } \\
\text { agrotóxicos, consumo de } \\
\text { alimentos defumados, } \\
\text { obesidade, inatividade } \\
\text { física, exposição } \\
\text { ocupacional, infecções } \\
\text { bacterianas }\end{array}$ & $\begin{array}{l}\text { Fatores de risco para } \\
\text { câncer: infecções virais } \\
\text { e bacterianas (51\%); } \\
\text { tabagismo (43\%); estresse } \\
(39 \%) \text {; substâncias químicas } \\
\text { (37\%); etilismo (22\%); } \\
\text { consumo de alimentos } \\
\text { defumados (21\%) }\end{array}$ \\
\hline Tanaka 42 & 2006 & Estudo experimental (ratos) & $\begin{array}{l}\text { Avaliar o efeito reprodutivo } \\
\text { e neurocomportamental do } \\
\text { corante tartrazina em ratos }\end{array}$ & Tartrazina & $\begin{array}{l}\text { A atividade motora foi maior } \\
\text { nos ratos machos ( } 259 \mathrm{mg} / \\
\mathrm{kg} / \mathrm{dia}) \text {. Não foi observado } \\
\text { nenhum efeito sobre a } \\
\text { reprodução }\end{array}$ \\
\hline $\begin{array}{l}\text { Moutinho } \\
\text { et al. } 2\end{array}$ & 2007 & $\begin{array}{l}\text { Estudo experimental } \\
\text { (ratos Wistar) }\end{array}$ & $\begin{array}{l}\text { Investigar o efeito do uso } \\
\text { prolongado do corante } \\
\text { tartrazina na mucosa } \\
\text { gástrica de ratos }\end{array}$ & Tartrazina & $\begin{array}{l}\uparrow \text { significativo de linfócitos } \\
\text { e eosinófilos na mucosa do } \\
\text { antro gástrico. Na dose de } \\
7,5 \mathrm{mg} \text { de tartrazina/kg/peso } \\
\text { (IDA) não foi observada } \\
\text { carcinogenicidade }\end{array}$ \\
\hline Elhkim et al. 28 & 2007 & Revisão sistemática/França & $\begin{array}{c}\text { Avaliar a segurança do } \\
\text { consumo do corante } \\
\text { tartrazina }\end{array}$ & Tartrazina & $\begin{array}{l}\text { Na França, o consumo } \\
\text { teórico máximo de tartrazina } \\
\text { foi de } 14,5 \% \text { (crianças) e } \\
32,2 \% \text { (adultos) da IDA }\end{array}$ \\
\hline $\begin{array}{l}\text { Ram \& } \\
\text { Ardem } 52\end{array}$ & 2007 & Meta-análise & $\begin{array}{l}\text { Avaliar o efeito da tartrazina } \\
\text { por meio de estudos de } \\
\text { exclusão ou desafio, na } \\
\text { exacerbação da asma }\end{array}$ & Tartrazina & $\begin{array}{l}\text { Dos } 90 \text { resumos avaliados, } \\
18 \text { foram considerados } \\
\text { relevantes. Destes, } 6 \\
\text { atendiam aos critérios de } \\
\text { inclusão. Em nenhum desses } \\
\text { estudos encontrou-se } \\
\text { resultados significativos para } \\
\text { a asma }\end{array}$ \\
\hline
\end{tabular}

DBPC: duplo-cego-placebo-controlado; AAS: ácido acetilsalisílico; BHT: antioxidante butil hidroxitolueno; BHA: antioxidante butil hidroxianisol; OFA: questionário de freqüência alimentar; IDA: ingestão diária aceitável. 
torno do déficit de atenção e hiperatividade. Já em relação à hipersensibilidade não específica, o número de estudos foi maior e os resultados mais consistentes quanto às manifestações clínicas de rinite, urticária e angioedema provocadas pelos aditivos, em particular pelos corantes artificiais.

Na literatura, os estudos dietéticos sobre a população infantil priorizam as deficiências nutricionais como a anemia ferropriva, hipovitaminose A, dentre outras, bem como o sobrepeso, obesidade e desnutrição 60,61,62. Agravos à saúde que sob o ponto de vista da saúde coletiva merecem investigação e intervenção precoce. Mas é preciso ter um olhar mais amplo para a saúde e nutrição do pré-escolar, pois diversos alimentos industrializados, que estão compondo cotidianamente a alimentação deste grupo apresentam aditivos alimentares e os mesmos podem provocar efeitos adversos à saúde.

Também é necessária a participação efetiva dos órgãos de regulação na vigilância desses produtos visando à proteção e promoção da saúde.

Enfim, os estudos de consumo de aditivos alimentares deveriam servir de base para a elaboração de estratégias para a vigilância alimentar e nutricional da população infantil, com a finalidade de reduzir o consumo dessas substancias e promover hábitos alimentares saudáveis. Também se coloca o desafio de conhecer a percepção de perigo de crianças e adultos - consumidores desses aditivos alimentares - no que tange aos riscos de ingestão continuada de aditivos alimentares para a saúde. Desafios imprescindíveis para o campo da saúde coletiva.

\section{Resumo}

Este estudo visa a contextualizar por meio de uma revisão sistemática da literatura, os riscos acarretados pelo consumo de aditivos alimentares. Em relação aos resultados dos estudos associando o consumo de aditivos ao aparecimento do câncer, os efeitos adversos à saúde foram observados principalmente nos estudos em que a Ingestão Diária Aceitável (IDA) foi excedida. Também apontou uma carência de pesquisas sobre o transtorno do déficit de atenção e hiperatividade. Já em relação à hipersensibilidade não específica, o número de estudos foi significativo e os resultados mais consistentes quanto às manifestações clínicas de rinite, urticária e angioedema provocadas pelos aditivos, em particular pelos os corantes artificiais. As crianças aparecem como grupo vulnerável, em razão do consumo potencial de alimentos com aditivos alimentares, particularmente corantes artificiais. Os resultados indicam que estudos de consumo de aditivos alimentares deveriam servir de base para a elaboração de estratégias de vigilância alimentar e nutricional, com a finalidade de promover hábitos alimentares saudáveis.

Aditivos Alimentares; Vigilância Nutricional; Doença Crônica; Hábitos Alimentares

\section{Colaboradores}

M. L. T. Polônio e F. Peres participaram de todas as etapas do artigo. 


\section{Referências}

1. Sandhi MB, Pinheiro ARO, Sichieri R, Monteiro CA, Filho MB, Schimidt MI. Análise da Estratégia Global para Alimentação, Atividade Física e Saúde, da Organização Mundial da Saúde. Epidemiol Serv Saúde 2005; 14:41-68.

2. Moutinho ILS, Bertges LC, Assis RVC. Prolonged use of food dye tartrazine (FD\&C yellow n ${ }^{\circ 5}$ ) and its effects on the gastric mucosa of Wistar rats. Braz J Biol 2007; 67:141-5.

3. Organización Mundial de la Salud. Norma general para los aditivos alimentarios. CODEX STAN 1995; 192.

4. Evangelista J. Definição e normas regulamentares. In: Evangelista J, organizador. Tecnologia de alimentos. 2a Ed. São Paulo: Editora Atheneu; 2000. p. 433-45.

5. Poulsen E. Case study: erythrosine. Food Addit Contam 1993; 10:315-23.

6. Pollock I. Hyperactivity and food additives. Bibl Nutr Dieta 1991; 48:81-9.

7. Willett WC. Dieta, nutrição e câncer. In: Shills ME, Olson JA, Moshi S, Rossi C, organizadores. Tratado de nutrição moderna na saúde e na doença. v. II. 9a Ed. Barueri: Editora Manole; 2003. p. 336-40.

8. Sugimura T, Wakabayashi K. Carcinogênios nos alimentos. In: Shills ME, Olson JA, Moshi S, Rossi C, organizadores. Tratado de nutrição moderna na saúde e na doença. v. II. 9ạ Ed. Barueri: Editora Manole; 2003. p. 1343-5.

9. Schilderman PAEL, ten Vaarwerk FJ, Lutgerink JT, Van der Wurff A, ten Hoor F, Kleinjans JC. Induction of oxidative DNA damage and early lesions in rat gastro-intestinal epithelium in relation to prostaglandin $\mathrm{H}$ synthase-mediated metabolism of butylated hydroxyanisole. Food Chem Toxicol 1995; 33:99-109.

10. World Health Organization. Joint FAO/WHO Expert Committee on Food Additives. Evaluation of certain food additives and contaminants. 37th report. Geneva: World Health Organization; 1991. (Clinical Report Series, 806).

11. Mulrow CD. Systematic reviews: rationale for systematic reviews. BMJ 1994; 309:597-9.

12. Rao P, Bhat RV, Sudershan RV. Exposure assessment to synthetic food colors of a selected population in Hyderabad, India. Food Addit Contam 2004; 21:415-21.

13. Husain A, Sawaya W, Al-Omair A, Al-Zenki S, AlAmiri H. Estimates of dietary exposure of children to artificial food colours in Kuwait. Food Addit Contam 2006; 23:245-51.

14. Nogueira RS. Consumo de corantes em produtos industrializados por pré-escolares: risco à saúde infantil [Trabalho de Conclusão de Curso]. Rio de Janeiro: Universidade Federal do Estado do Rio de Janeiro; 2004.

15. Freitas VPS, Brígido BM, Mazon EMAM, Martini MH, Passos MHCR. Avaliação da qualidade de doces em massa tipo junino. Hig Aliment 2006; 20:75-82.

16. Angelucci E. Corantes naturais versus corantes artificiais. In: Carvalho PRD, organizador. Corantes naturais para alimentos. Campinas: Instituto de Tecnologia de Alimentos; 1988. p. 1-15.
17. Prado MA, Godoy HT. Teores de corantes artificiais em alimentos determinados por cromatografia líquida de alta eficiência. Química Nova 2007; 30:268-73.

18. Alves B, Abrantes SMP. Avaliação das bebidas não alcoólicas e não gaseificadas, em relação ao uso de corantes artificiais. Hig Aliment 2003; 18:51-4.

19. Resende ALS, Mattos IE, Koifman S. Dieta e câncer gástrico: aspectos históricos associados ao padrão de consumo alimentar no Estado do Pará. Rev Nutr 2006; 19:511-9.

20. Garafolo A, Avesani CM, Camargo KG, Barros ME, Silva SRJ, Taddey JAA, et al. Dieta e câncer: um enfoque epidemiológico. Rev Nutr 2004; 17:491-505.

21. Santos Jr. JC. Câncer ano-reto-cólico: aspectos atuais IV - câncer de colón - fatores clínicos, epidemiológicos e preventivos. Revista Brasileira de Coloproctologia 2007; 28:378-85.

22. Willett WC, MacMahan B. Diet and cancer: an overview (Part 2). N Engl J Med 1984; 310:697-704.

23. Willian W, Cajas-Salazar N, Salama AS. Factors contributing to discrepancies in population monitoring studies. Mutat Res 1998; 400:467-78.

24. Laver $\mathrm{K}$. The history of nitrite in human nutrition: a contribution from German cookery books. J Clin Epidemiol 1991; 44:261-4.

25. Hill HJ. Food additives and contaminants and their contribution to the human cancer load. Eur J Cancer Prev 1993; 2:291-5.

26. SugimuraT. Mutagens, carcinogens, and tumor promoters in our daily food. Cancer 1982; 49:1970-84

27. Antunes LMG, Araújo MCP. Mutagenicidade e antigenicidade dos principais corantes para alimentos. Rev Nutr 2000; 13:81-8.

28. Elhkim MO, Héraud F, Bemrah N, Gauchard F, Lorino T, Lambré C, et al. New considerations regarding the risk assessment on Tartrazine: an update toxicological assessment, intolerance reactions and maximum theoretical daily intake in France. Regul Toxicol Pharmacol 2007; 47:308-16.

29. Abdel-Aziz AH, Shouman SA, Attia AS, Saad SF. A study on the reproductive toxicity of erythrosine in male mice. Pharmacol Res 1997; 35:457-62.

30. Inoue M, Iwasaki M, Otani T, Sasazuki S, Tsugane S. Public awareness of risk factors for cancer among the Japanese general population: a populationbased survey. BMC Public Health 2006; 6:2415-21.

31. García M, Fernández E, Borras JM, Nieto JF, Schiaffino A, Peris M, et al. Cancer risk perceptions in an Urban Mediterranean population. Int J Cancer 2005; 117:132-6.

32. Sasaki YF, Kawaguchi S, Kamaya A, Ohshita M, Kabasawa K, Iwama K, et al. The comet with 8 mouse organs: results with 39 currently used food additives. Mutat Res 2002; 519:103-19.

33. Barkley RA. Attention-deficit hyperactivity disorder: a handbook for diagnosis and treatment. New York: Guildford Press; 1990

34. Carter CM, Urbanowicz M, Hemsley R, Mantilla L, Strobel S, Graham PJ, et al. Effects of a few food diet in attention deficit disorder. Arch Dis Child 1993; 69:564-8. 
35. American Psychiatric Association. DSM-IV-R Manual Diagnóstico e Estatístico de Transtornos Mentais. 4a Ed. Porto Alegre: Editora Artes Médicas; 1994.

36. Vasconcelos MM, Werner Jr. J, Malheiros AFA, Lima DFN, Santos ISSO, Barbosa JB. Prevalência do transtorno de déficit de atenção/hiperatividade. Arq Neuropsiquiatr 2003; 61:67-73.

37. Braga R. O comportamento hiperativo na infância. Curitiba: Conscientia; 1998.

38. Boris M, Mandel FS. Foods and additives are common causes of attention deficit hyperactivity disorder in children. Ann Allergy 1994; 72:462-8.

39. Feingold BF. Why your child is hyperactive? New York: Random House; 1975.

40. Hughes MC, Hatsukami DK, Mitchell JE, Dahlgren LA. Hyperactivity and the attention-deficit disorders. Am J Psychiatry 1986; 27:119-26.

41. Goldstein S. O que é hiperatividade? In: Goldstein S, Goldstein M, Organizadores. Hiperatividade: como desenvolver a capacidade de atenção da criança. 2a Ed. Campinas: Editora Papirus; 1996. p. 19-29.

42. Tanaka T. Reproductive and neurobehavioural toxicity study of tartrazine administered to mice in the diet. Food Chem Toxicol 2006; 44:179-87.

43. Antilo A, Bernadino L. The role of additives in chronic pseudo-allergic dermatopathies from food intolerance. Allerg Immunol (Paris) 1995; 27:157-60.

44. Balbani APS, Stelzer LB, Montovani JC. Excipientes de medicamentos e as informações da bula. Rev Bras Otorrinolaringol 2006; 72:400-6.

45. Castanheira I, Oliveira L, Valente A, Alvito P, Costa HS, Alink A. The need for reference materials when monitoring nitrate intake. Anal Bioanal Chem 2004; 378:1232-8.

46. Montaño-García ML, Orea-Solano M. Estudio de la frecuencia de urticaria y angioedema inducidos por aditivos de alimentos. Alergia Méx 1989; 36:15-8

47. Morales RH. Reacciones adversas a alimentos y sus aditivos. Pediatr Día 1998; 14:128-31.

48. Hinton DM. Immunotoxicity test applied to direct food and colour additives: US FDA "Red book II" guidelines. Hum Exp Toxicol 1995; 14:143-5.

49. Tabar AI, Acero S, Arregui C, Urdánoz M, Quirce S. Asma y alergia por el colorante carmín. An Sits Sanit Navar 2003; 26 Suppl 2:65-73.
50. Tabar-Purroy AI, Acero S, Garcia BE, Echechipia S, Quirce S. Carmine(E-120)-induced occupational asthma revisited. J Allergy Clin Immunol 2003; 111:415-9.

51. Nettis E, Colanardi MC, Ferrennini A, Tursi A. Suspected tartrazine-induced acute urticaria/angioedema is only rarely reproducible by oral rechallengers. Clin Exp Allergy 2003; 33:1725-9.

52. Ram FS, Ardem KJ. Tartrazine exclusion for allergic asthma (Review). Cochrane Database Syst Rev 2001; (4):CD000460.

53. Worm M, Vieth W, Ehlers I, Sterry W, Zuberbier T. Increased leukotriene production by food additives in patients with atopic dermatitis and proven food intolerance. Clin Exp Allergy 2001; 31:265-73.

54. Di Lorenzo G, Pacor ML, Vignola AM, Profita M, Espósito-Pellitteri M, Biasi D, et al. Urinary metabolites of histamine and leukotrienes before and after placebo-controlled challenge with ASA and food additives in chronic urticaria patients. Allergy 2002; 57:1180-6.

55. Inomata N, Osuna H, Fujita H, Ogawa T, Ikezawa Z Multiple chemical sensitivities following intolerance to azo dye in sweets in a 5-year-old girl. Allergol Int 2006; 55:203-5.

56. Asero R. Multiple intolerance to food additives. J Allergy Clin Immunol 2002; 110:531-2.

57. Guerrero-Núñez MGB. Urticaria. Alergia Méx 1997 44:17-22

58. Nain MP. Toxicologie expérimentale du colorant tartrazine. Médecine et Nutrition 1993; XIX:365-74.

59. Garcia RWD. Reflexos da globalização na cultura alimentar: considerações sobre as mudanças na alimentação urbana. Rev Nutr 2003; 16:483-92.

60. Tuma RCFB, Costa THM, Schimitz BAS. Avaliação antropométrica e dietética de pré-escolares em três creches de Brasília, Distrito Federal. Rev Bras Saúde Matern Infant 2005; 5:419-28.

61. Bueno MB, Fisberg RM. Comparação de três critérios de classificação de sobrepeso e obesidade entre pré-escolares. Rev Bras Saúde Matern Infant 2006; 6:411-7.

62. Assunção MC, Santos IS, Barros AJD, Gigante DP Victora CG. Efeito da fortificação de farinhas com ferro sobre anemia em pré-escolares, Pelotas, RS. Rev Saúde Pública 2007; 41:539-48.

Recebido em 10/Nov/2008

Versão final reapresentada em 13/Abr/2009 Aprovado em 20/Abr/2009 